\title{
Ultrasensitive Detection of Exosomes by Target Triggered 3D DNA Walking Machine and Exonuclease III-Assisted Electrochemical Ratiometric Biosensing
}

Li Zhao, Ruijiao Sun, Peng He and Xiaoru Zhang*

Key Laboratory of Optic-electric Sensing and Analytical Chemistry for Life Science, MOE; Shandong Key Laboratory of Biochemical Analysis; College of Chemistry and Molecular Engineering. Qingdao University of Science and Technology, Qingdao 266042, PR China.

*Corresponding authors: Xiaoru Zhang, E-mail: zhangxr7407@126.com, Tel: 0086-532-84022693

\section{Table of contents:}

Table S1 Sequence information for oligonucleotides used in this work

Figure S1 UV-visible absorption spectra characterization

Figure S2 Agarose gel electrophoresis

S-3

Figure S3 Optimizations of experimental conditions for DNAzyme walker part

Figure S4 Optimizations of experimental conditions for electrochemical assay pare

Table S2 Comparison of the detection linear range

Figure S5 Detection of EpCAM by WB

References

S-6 
Table S1. Sequence Information for Oligonucleotides Used in This Work

\begin{tabular}{|c|c|}
\hline Name & Sequences $\left(5^{\prime} \rightarrow 3^{\prime}\right)$ \\
\hline Substrate & Bio-(T) ${ }_{14} \mathrm{C}$ ACTATrAGGAAGAGACGGACAACTA \\
\hline $\begin{array}{l}\text { Substrate- } \\
\text { 6-FAM }\end{array}$ & $\begin{array}{l}\text { Bio-(T) }{ }_{14} \text { CACTATrAGGAAGAGACGGACAACTA-6-Carboxyfluorescein } \\
(6-F A M)\end{array}$ \\
\hline $\begin{array}{l}\text { Swing arm } \\
\text { (EpCAM } \\
\text { aptamer+ } \\
\text { DNAzyme) }\end{array}$ & $\begin{array}{l}\text { CAC TAC AGA GGT TGC GTC TGT CCC ACG TTG TCA TGG GGG GTT } \\
\text { GGC CTG }(\mathrm{T})_{30} \mathrm{C} \underline{\underline{\text { TC TCT TCT CCG AGC CGG TCG AAA TAG T }}}\end{array}$ \\
\hline CD63 aptamer & Bio-(T) ${ }_{25}$ CAC CCC ACC TCG CTC CCG TGA CAC TAA TGC TA \\
\hline mDNA & GGAAGAGACGGACAACTA \\
\hline MB-DNA & HS-SH-C6-GCTAGACGGTGTTCCCTTCCTTCCTGTCCGTCTC TTCC-MB \\
\hline Fc-DNA & CCGTCTAGC-Fc \\
\hline $\begin{array}{l}\text { Random } \\
\text { sequence }\end{array}$ & $\begin{array}{l}\text { TTTTTTTTTTTTTTTTTTTTTTTTTTTTTTTTTTTTTTTTTTTTTTTTTTTT } \\
\text { TTTTTTTTTTTTTTTTTTTTTTTTTTCTCTCTTCTCCGAGCCGGTCGAAA } \\
\text { TAGT }\end{array}$ \\
\hline
\end{tabular}


UV- visible absorption spectra characterization
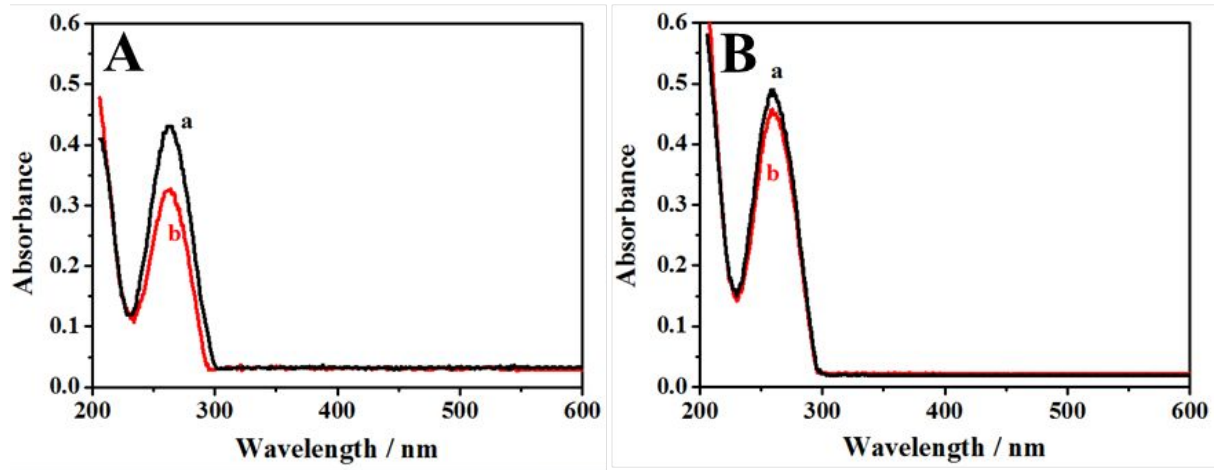

Figure S1. (A) UV-visible absorption spectra of biotin-strands in the supernatant. (B) UV-visible absorption spectra of non-biotinylated strands in the supernatant. (a) Before and (b) after incubation with streptavidin-MBs.

The feasibility for electrochemical assay part verified by agarose gel electrophoresis
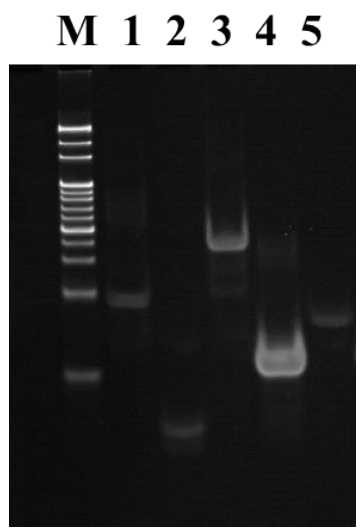

Figure S2. PAGE analysis: lane 1, MB-DNA; lane 2, mDNA; lane 3, MB-DNA + mDNA; lane 4, MB-DNA + mDNA + Exo III; lane 5, MB-DNA + mDNA + Exo III + Fc DNA

\section{Optimizations of Experimental Conditions.}

In order to enhance the detection sensitivity, various experiment conditions were tested. In the target-triggered DNAzyme walker part, the molar ratio between substrate and CD 63 aptamer on MBs, $\mathrm{pH}$, the reaction time, the concentration of $\mathrm{Mg}^{2+}$ and swing arm were important to the performance of DNA walker.

From the results of Figure S3, we could observe that the optimized conditions were selected as follows: the ratio of substrate to $\mathrm{CD} 63$ aptamer was $100: 1, \mathrm{pH}$ was 8.3 , reaction time for walker was 
$10 \mathrm{~h}$, concentrations of $\mathrm{Mg}^{2+}$ and swing arm were $20 \mathrm{mM}$ and $25 \mathrm{nM}$ respectively.

In the electrochemical assay part, detection conditions such as the concentration of Exo III as well as the reaction time of Exo III were optimized. As shown in Figure S4, in presence of $1.0 \times 10^{9}$ particles $/ \mathrm{mL}$ exosome, the $\mathrm{I}_{\mathrm{Fc}} / \mathrm{I}_{\mathrm{MB}}$ values changed with the concentration of Exo III (Figure S4A) and the reaction time of Exo III (Figure S4B). When $3 \mathrm{U} / \mu \mathrm{L}$ Exo III was added and reacted for $120 \mathrm{~min}$, optimized electrochemical signals were obtained.
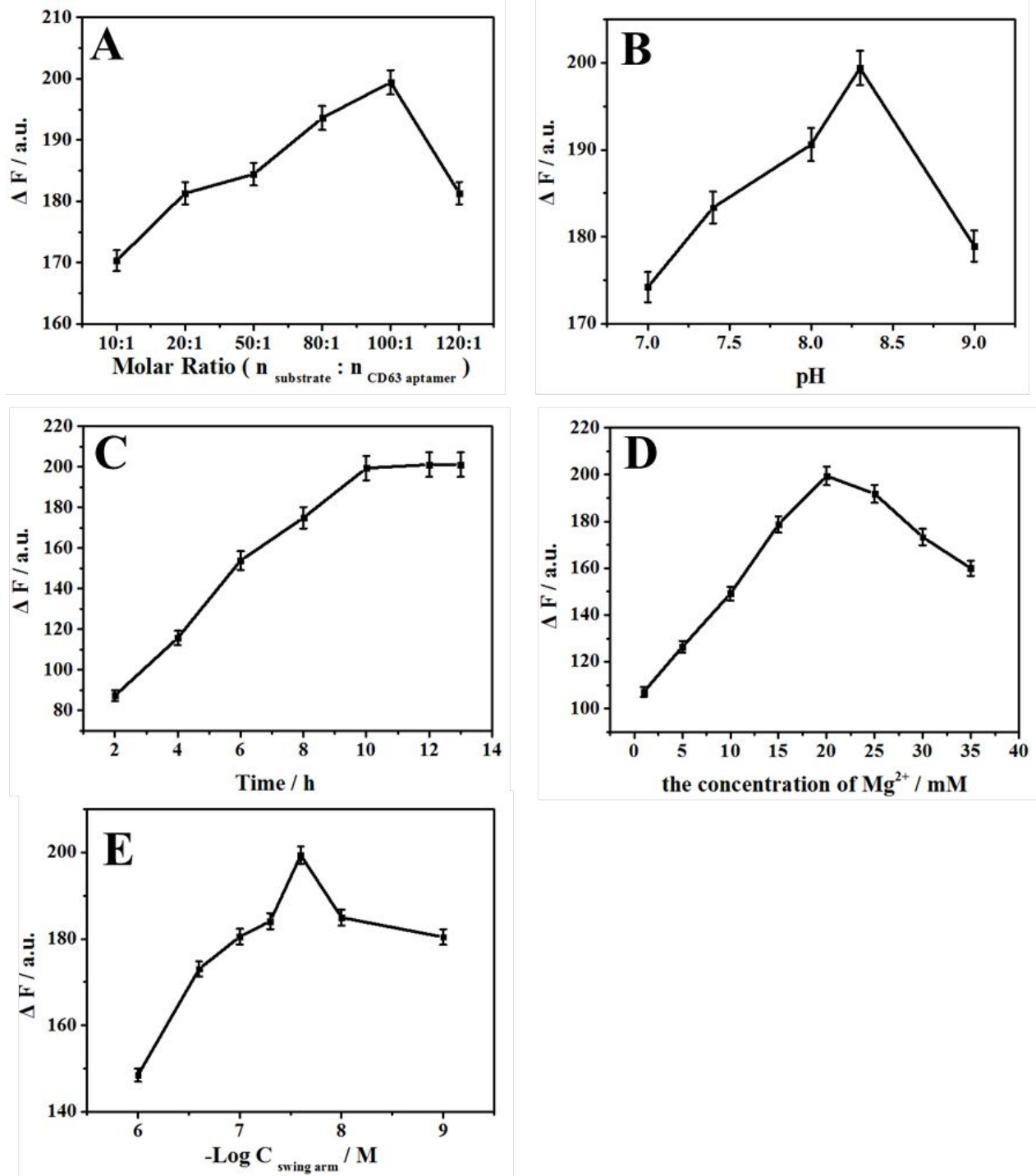

Figure S3. Optimization of DNAzyme walker part by fluorescence assay. ( A ) Molar Ratio ( $\mathrm{n}_{\text {substrate }}$ : $\mathrm{n}_{\text {aptamer }}$ ); (B) the $\mathrm{pH}$ of buffer solution; (C) the reaction time of swing arm; (D) concentration of $\mathrm{Mg}^{2+}$; (E) concentration of DNAzyme. 

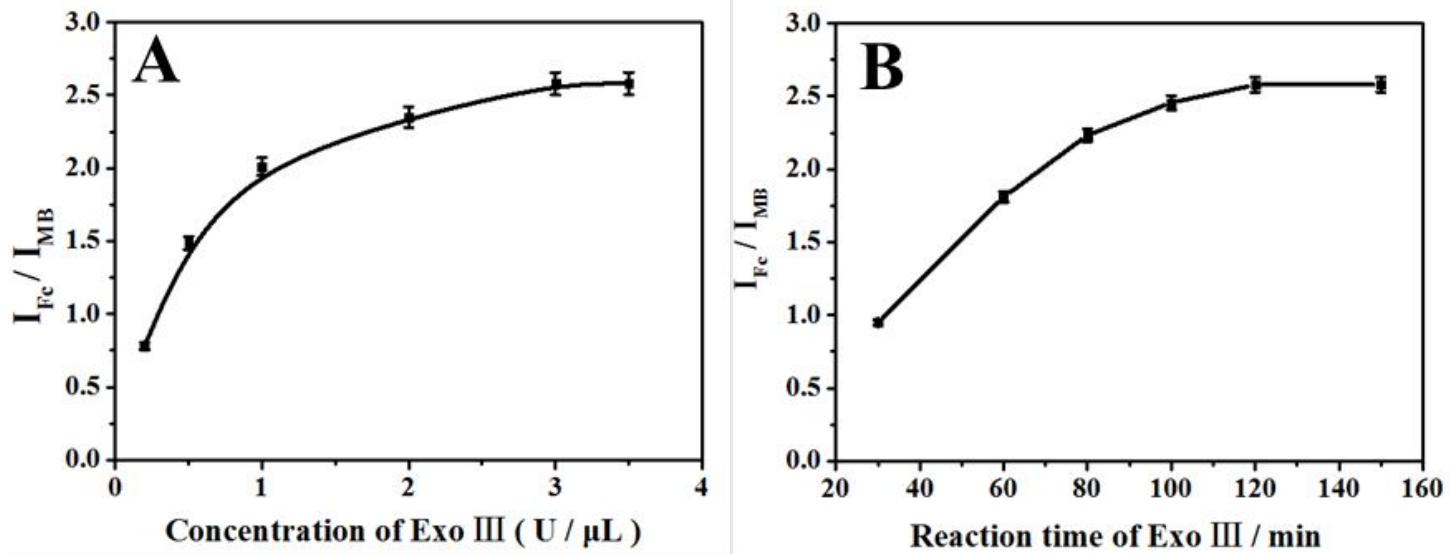

Figure S4. The optimization of (A) the amount of Exo III and (B) the reaction time of Exo III.

Table S2. Comparison of the detection linear range about current methods for the exosomes detection

\begin{tabular}{|l|c|c|}
\hline \multicolumn{1}{|c|}{ Method } & $\begin{array}{c}\text { Linear range } \\
\text { (particles/mL) }\end{array}$ & Ref. \\
\hline copper-mediated exosome detection & $7.5 \times 10^{7}-1.5 \times 10^{10}$ & 1 \\
\hline paper-based aptasensor & $1.0 \times 10^{7}-1.0 \times 10^{11}$ & 2 \\
\hline DNA-capped s-SWCNTs aptasensor & $1.84 \times 10^{9}-2.21 \times 10^{10}$ & 3 \\
\hline electrochemical immunosensor & $1.0 \times 10^{5}-1.0 \times 10^{9}$ & 4 \\
\hline optofluidic for exosome detection & $1.0 \times 10^{7}-1.0 \times 10^{11}$ & 5 \\
\hline aptamer-magnetic bead bioconjugates & $1.0 \times 10^{6}-1.2 \times 10^{8}$ & 6 \\
\hline quantum dot-based detection & $1.0 \times 10^{5}-1.0 \times 10^{10}$ & 7 \\
\hline electrochemical method & $1.0 \times 10^{5}-1.0 \times 10^{12}$ & 8 \\
\hline lateral flow immunoassay & $9.0 \times 10^{9}-1.44 \times 10^{11}$ & 9 \\
\hline enzyme-linked HCR method & $2.3 \times 10^{6}-2.3 \times 10^{8}$ & 10 \\
\hline DNAzyme walker amplified electrochemical assay & $5.0 \times 10^{4}-1.0 \times 10^{10}$ & This work \\
\hline
\end{tabular}

EpCAM 293T Hela MCF-7

$39 \mathrm{kD}+2 \mathrm{Exo}$

Figure S5. Detection of EpCAM from HEK-293T cell, Hela cell and MCF-7 cell by WB.

\section{REFERENCES}

(1) Fang, H.; Jing, W.; Bin, C. Y. Anal. Chem. 2018, 90, 8072-8079.

(2) Chen, X.; Lan, J.; Liu, Y. Biosens. Bioelectron. 2017, 102, 582-588. 
(3) Xia, Y.; Liu, M.; Wang, L. Biosens. Bioelectron. 2017, 92, 8-15.

(4) Doldán, X.; Fagúndez, P.; Cayota, A. Anal. Chem. 2016, 88, 10466-10473.

(5) Ko, J.; Hemphill, M. A.; Gabrieli, D. Scientific Reports, 2016, 6, 31215.

(6) Dong, H.; Chen, H.; Jiang, J. Anal. Chem. 2018, 90, 4507-4513.

(7) Ko, J.; Hemphill, M. A.; Gabrieli, D. Scientific Reports, 2016, 6, 31215.

(8) Wang, S.; Zhang, L.; Wan, S. ACS Nano. 2017, 11, 3943-3949.

(9) Myriam, O. R.; Sheila, L. C.; Reyburn, H. T. Journal of Extracellular Vesicles. 2016, 5, 31803.

(10) He, F.; Liu, H.; Guo, X. Anal. Chem. 2017, 89, 12968-12975. 